\title{
Chapter 10 \\ Contamination of Wild Animals: \\ Microhabitat Heterogeneity and Ecological \\ Factors of Radioactive Cesium Exposure in Fukushima
}

\author{
Ken Ishida
}

\begin{abstract}
Wildlife, mainly 69 bird (Aves) species, has been observed in Abukuma Mountains, northeastern Fukushima Prefecture, which is the most radioactively contaminated area, over the seasons since July 2011. However, it is still unclear whether the changes in the bird community have been caused by the radioactive contamination and/or by changes in human activity, adding to the natural dynamics. The aerial dose rate at the survey area was initially estimated to be more than $100 \mu \mathrm{Sv} / \mathrm{h}$ (mainly ${ }^{137} \mathrm{Cs},{ }^{134} \mathrm{Cs}$, and ${ }^{131} \mathrm{I}$ ), which decreased in the summer of 2014 to $0.1-20 \mu \mathrm{Sv} / \mathrm{h}$ (mainly ${ }^{137} \mathrm{Cs}$ and ${ }^{134} \mathrm{Cs}$ ). Radioactivity in wild habitats is heterogeneous among the microhabitats and is dynamic through time and seasonal conditions. Microhabitat radio-heterogeneity was clearly indicated by the 2-month-long measurement with 200 dosimeter badges in this study. The ecological factors related to free living (in-situ) wildlife in the highly contaminated area of Fukushima are discussed.
\end{abstract}

Keywords Free-living - Wildlife - Microhabitat • Ecosystem • Radiation • Heterogeneity $\bullet$ Dynamics $\bullet$ Long term $\bullet$ Fukushima $\bullet$ Bush-warbler

\subsection{Introduction}

Monitoring the ways in which free-living animals, say in-situ wildlife, experience changing radiation levels and other environmental factors at Fukushima and Chernobyl (where the severe, IAEA rank seven, nuclear power accidents have been experienced), is crucial for the future world of higher radiation levels (Akimoto 2014; Hiyama et al. 2012; Ishida 2013; Møller et al. 2013). Since March 11, 2011, highly contaminated areas stretch northwestward from the Fukushima Daiichi nuclear power plant (F1NPP), to the northern Abukuma highland, Fukushima

K. Ishida $(\bowtie)$

Graduate School of Agricultural and Life Sciences, The University of Tokyo, 1-1-1, Yayoi,

Bunkyo-ku, Tokyo 113-8657, Japan

e-mail: ishiken@es.a.u-tokyo.ac.jp 


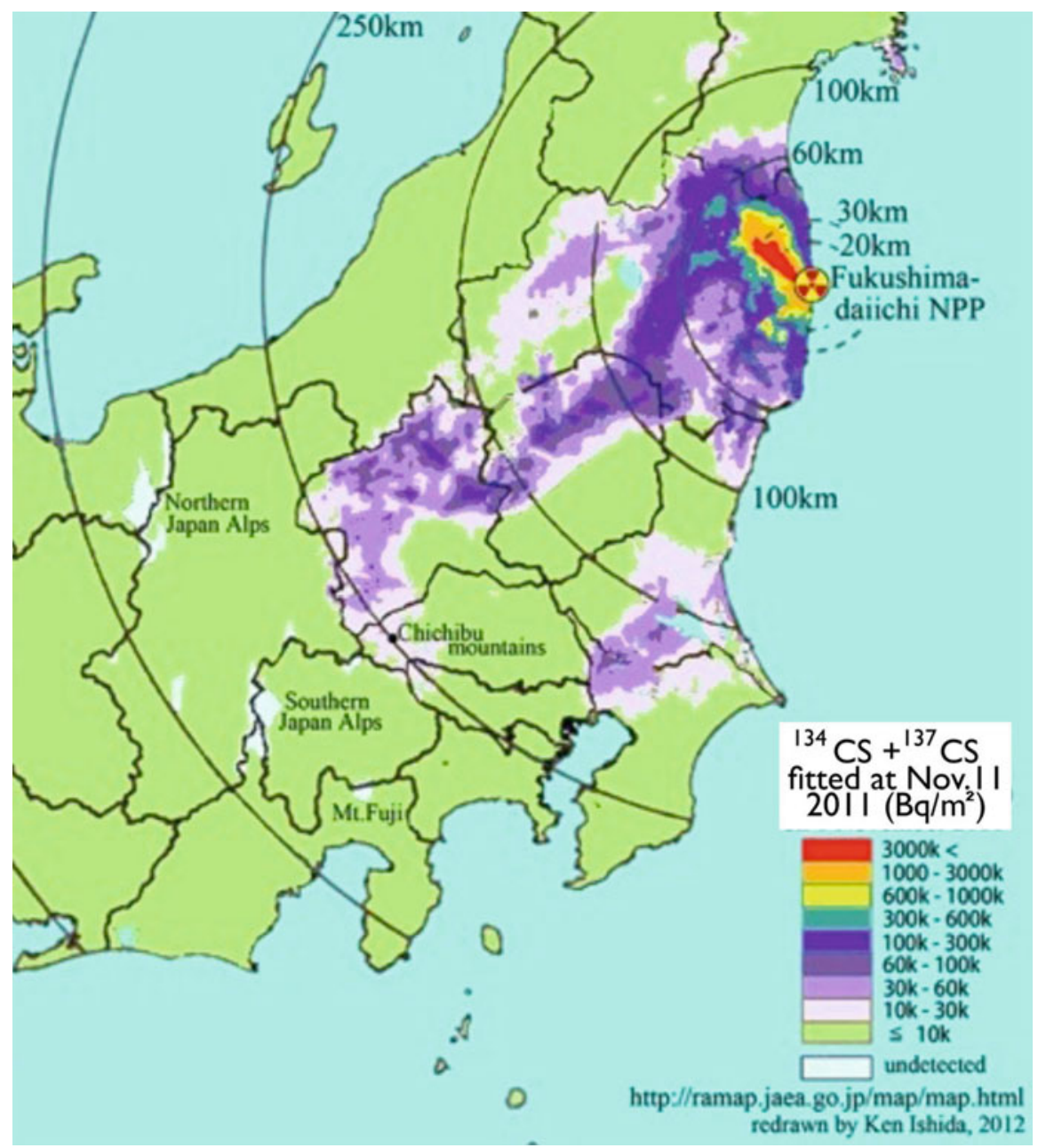

Fig. 10.1 Map of radiation fallout distribution and the location of the study area

Prefecture, Japan (Figs. 10.1, 10.2, and 10.3). The landscape of this area comprises paddy field, farmlands, natural and artificial forests, grasslands, ponds, and streams, where the biodiversity is directly related to the habitat heterogeneity. The aerial dose rates were initially estimated to be more than $100 \mu \mathrm{Sv} / \mathrm{h}$ at some hot spots even farther than $30 \mathrm{~km}$ from the F1NPP. For example, the maximum value was $170 \mu \mathrm{Sv} / \mathrm{h}$ at Techiro, Akaugi, Namie, Fukushima during spring prior to new plant growth and prior to breeding for most birds and other animals (estimated on March 16, 2011, Ministry of Education, Culture, Sports, Science and Technology, Japan (MEXT) 2011). Within the habitat, there were about 15 terrestrial mammals including the macaque monkey (Macaca fuscata) and about 70 birds including the bush warbler (Cettia diphone). I first describe the dominant bird species, habitat 
Fig. 10.2 Map of Abukuma Mountains, Fukushima Daiichi nuclear power plant (F1NPP), the three main study sites (Akaugi and Omaru of Namie Town, and Yamakiya of Kawamata Town). The yellow line at the center indicates the $55-\mathrm{km}$ long section from F1NPP to Abukuma River, the vertical profile of which is shown in Fig. 10.3

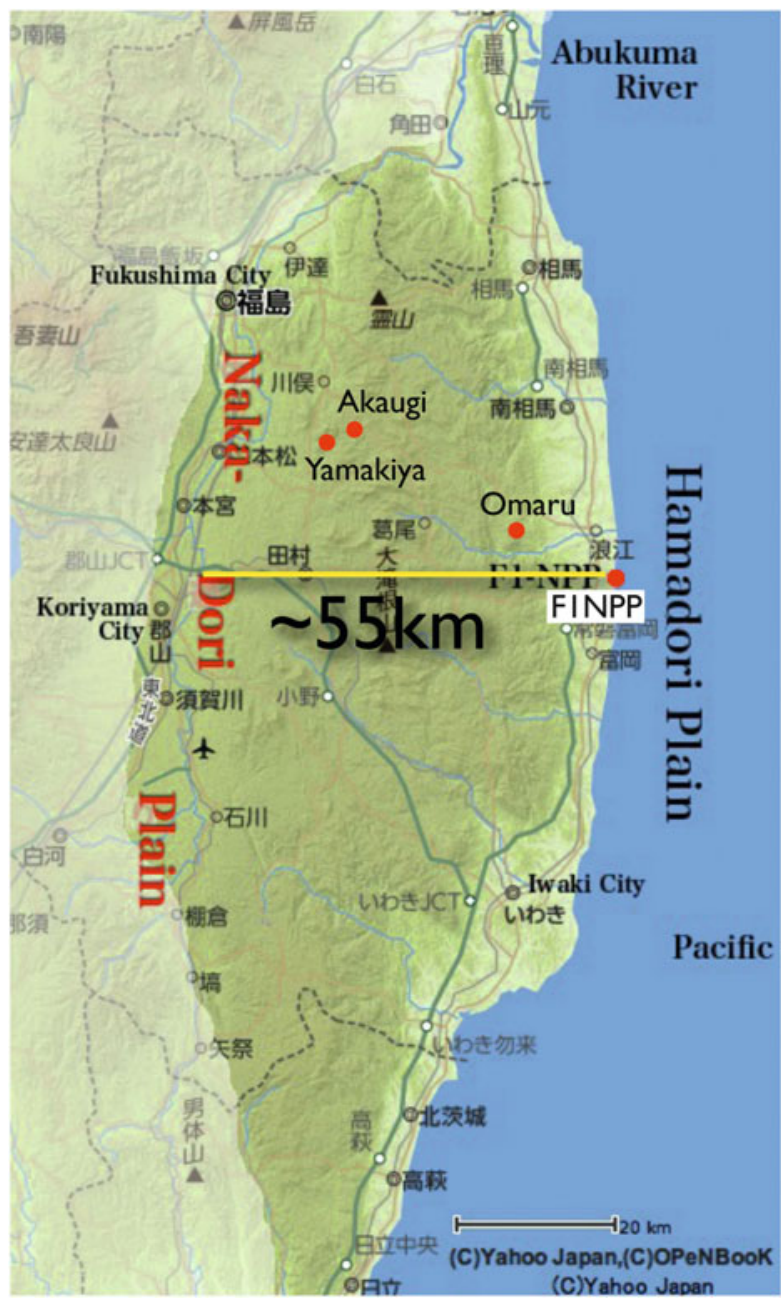

heterogeneity through the study area, and microhabitat radiation heterogeneity in it. Then I will discuss on the analyses and future gain of long term monitoring of free-living birds.

\subsection{Landscape, Climate, and Biodiversity of Abukuma Highlands}

A description of the Abukuma Mountains was given in the previous volume (Ishida 2013). Here I explain the detailed characteristics of the habitats, which relate to wildlife radiation exposure and biodiversity of the most highly contaminated areas. 


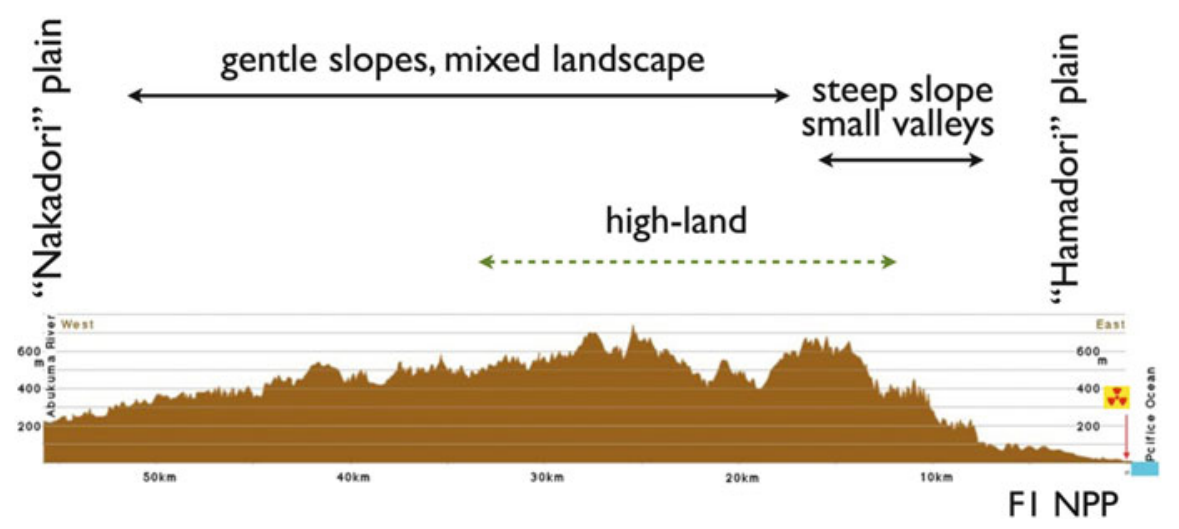

Fig. 10.3 Topological profile and landscape characteristics along the 55-km East-West line from F1NPP to Abukuma River, or Koriyama City (Refer to the yellow line in Fig. 10.2)

I define a "high" contamination area as that in which the estimated fallout of total ${ }^{137} \mathrm{Cs}$ and ${ }^{134} \mathrm{Cs}$ is more than $3000 \mathrm{kBq} / \mathrm{m}^{2}$ (red area in Figs. 10.1 and 10.4), and "low" or "none" contamination areas in which the contamination is less than $1000 \mathrm{kBq} / \mathrm{m}^{2}$ (yellow, mauve to green in Figs. 10.1 and 10.4). I explain why I do not use the measurements of dose rates recorded at each place for comparison in Sect. 10.4.

The F1NPP reactors are located on the eastern Pacific coast (Fig. 10.2). The closest to F1NPP reactors and most highly contaminated area is in the narrow flat plain of 5-10 km (Hamadori Plain). This region comprises residential areas among paddies and farmland (Fig. 10.3). Next to this plain is a steep slope with small valleys covered by a forest of coniferous plantations, secondary pine, and deciduous trees. The elevation increases quickly up to about $400 \mathrm{~m}$ and the slope of this part of the eastern side functions as a radiative shield. Such terrain effects were also indicated at in farther areas such as Chichibu Mountains (the southwestern edge of the contamination area expanding to $250 \mathrm{~km}$ from FINPP) and Iide Mountains (150 km west) as outlined in the MEXT report (2011, pp. 25-26).

The western area contains a highland plateau with many small hills about $600 \mathrm{~m}$ above sea level. The highest peak of Mt. Ootakine is $1192 \mathrm{~m}$, the next Mt. Hiyama $1057 \mathrm{~m}$, and the others are less than $1000 \mathrm{~m}$. This highland plateau comprises a scattering of paddies, farmland, pastures, orchards, coniferous and deciduous forests, grasslands, streams, and ponds. Habitat heterogeneity and biodiversity are highest around this landscape. On the western side of Abukuma Mountains is a gentle slope with low hills, farmland, and forest (Fig. 10.3), which connects to the eastern highland plateau (it should be noted that there is no distinct border between these regions). Less of this area has been developed into agricultural fields as compared to the East, and more people live toward the West of Abukuma River. Along this river, there were several central cities of the Fukushima Prefecture, such as Koriyama, Nihonmatsu, and Fukushima (Nakadori Plain). 


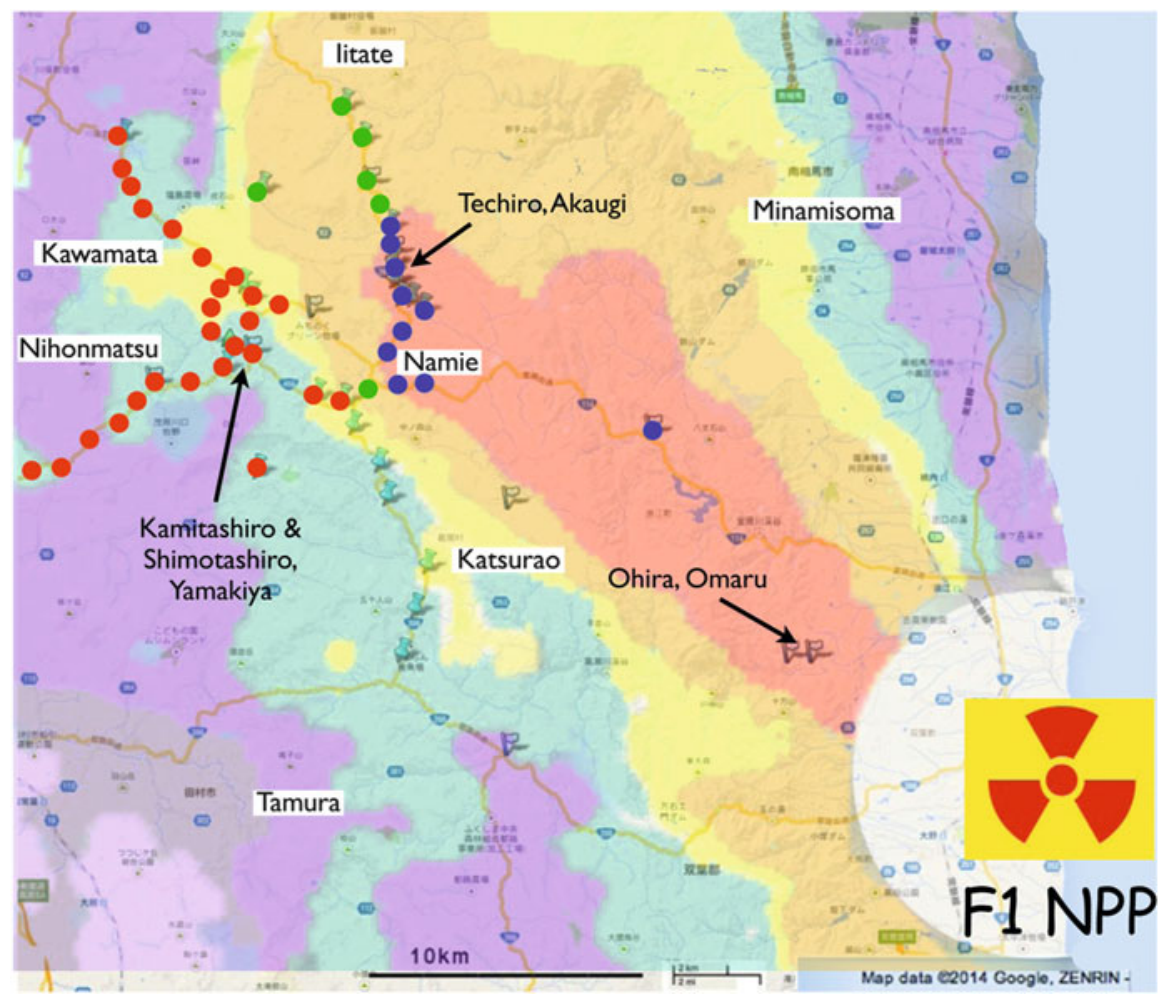

Fig. 10.4 Sites of early morning bird point count survey and microhabitat aerial dose rate measurements: Blue dots indicate the sites in the highest $\left(>3000 \mathrm{kBq} / \mathrm{m}^{2}\right)$, greens in the middle $\left(1000-3000 \mathrm{kBq} / \mathrm{m}^{2}\right)$, reds in the lower $\left(<1000 \mathrm{kBq} / \mathrm{m}^{2}\right)$ contamination areas. Not all the sites are presented here

There are significant seasonal changes evident by the following phenomenon: rapid plant growth in spring (April to May); a flash of insects and other small animals such as frogs and spiders in summer (June to August); leaf coloring and falling in autumn (September to November); and snow accumulation in winter mainly on the highland plateau (December to March, Fig. 10.5). On March 11,2011 , there was some snow cover left on the ground in the highlands, and most plants and animals were not yet active or had not yet arrived for breeding. Large areas, except the eastern steep slope, is occupied by paddy fields, which also undergo significant seasonal changes; water flooding during the growth of rice and rapid growth of rice stems, which is then followed by the disappearance of both during autumn. The paddy fields are surrounded by streams and forests (see also Fig. 12.3 in Ishida 2013). 


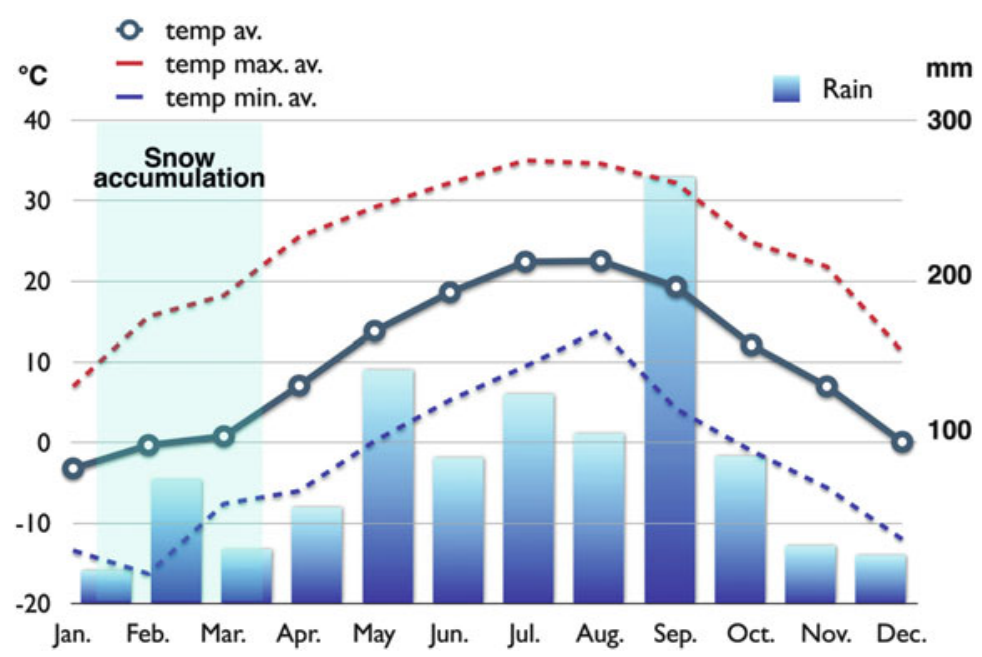

Fig. 10.5 Climate of Iitate Village, data from Japan Meteorological Agency for 2011: there is snow accumulation during January to March, more rainfall in early summer, and seasonal temperate change. Sometime typhoons (tropical cyclones) bring much rain in late summer or early autumn

\subsection{Bird Communities in the Northern Abukuma Highlands}

The author observed 69 bird species during 25 surveys in the study area from July 2011 to August 2014. During 5-min point count surveys (Møller et al. 2013), which were conducted in the early mornings of mid-June (3:40-9:00 a.m.), 3-13 species were recorded at each count (Figs. 10.4 and 10.6). I recorded fewer species in the high contamination area and more species in the intermediate and low radiation areas in 2012, although the differences were not statistically significant $(\mathrm{P}>0.05$, Mann-Whitney $U$-test). After 1 April 2013, entrance was restricted by law, and I could only perform a few early morning point counts within the area. So the range, average, and standard deviation of the number of observed species in only the low contamination area are shown for 2013 and 2014 in Fig. 10.6. These data illustrate the agreement on that the degree of diversity was lower for bird and butterfly species and higher for spiders in the high contamination areas in Fukushima (Fig. 10.3 in their paper, Møller et al. 2013). This mixed result may have arisen from of habitat diversity change, radiation, and/or human activities.

The 10 most dominant species in the point count survey were almost common during the 3 years of observed breeding seasons (Table 10.1). In addition, the three most dominant species, Cettia diphone, Hypsipetes amourotis, and Emberiza cioides, were also consistent in their ranking order, and four other species, Cuculus policephalus, Corvus macrorhynchos, Parus minor, and Phasianus versicolor were always in the list and have been frequently recorded. C. policephalus is a parasite of 
Fig. 10.6 Bird species richness estimated with early morning point count surveys in mid-June: the survey within the higher contamination area $\left(1000 \mathrm{kBq} / \mathrm{m}^{2}\right)$ was restricted since April 2013. Average and ranges (minimum, standard deviation, and maximum) of species numbers recorded are shown for the 3 years of 2012-2013, only for the low radiation $\left(<1000 \mathrm{kBq} / \mathrm{m}^{2}\right)$ district

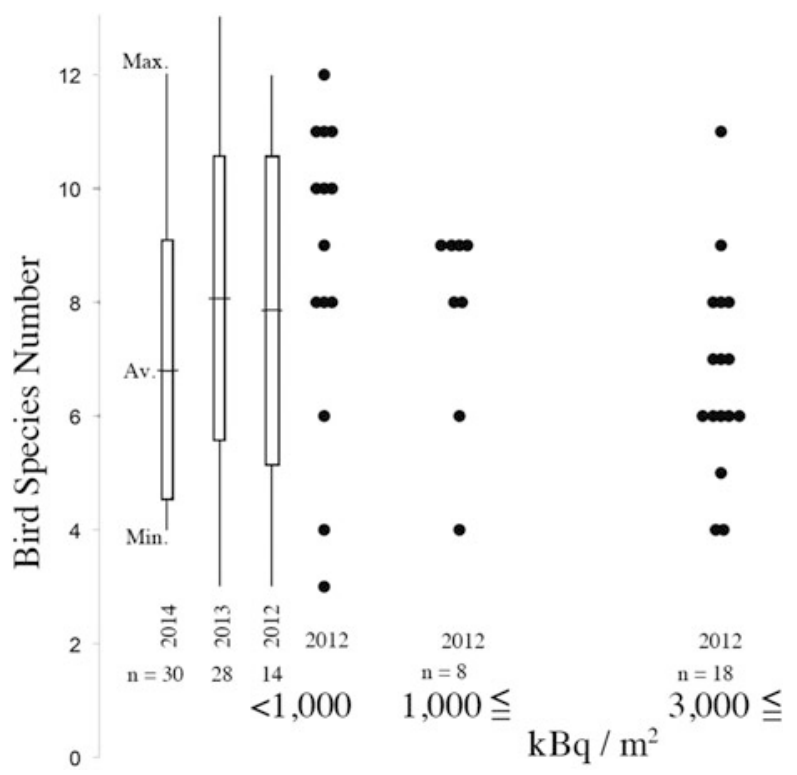

Table 10.1 Ten dominant species of birds in point count survey (observation frequency rate)

\begin{tabular}{|c|c|c|c|c|c|}
\hline \multicolumn{6}{|c|}{ Rates are per 38,34 , and 33 counts in each year } \\
\hline \multicolumn{2}{|l|}{2012} & \multicolumn{2}{|l|}{2013} & \multicolumn{2}{|l|}{2014} \\
\hline Cettia dipohne & 0.84 & C. dipohne & 1.00 & C. dipohne & 0.97 \\
\hline $\begin{array}{l}\text { Hypsipetes } \\
\text { amourotis }\end{array}$ & 0.76 & H. amourotis & 0.94 & H. amourotis & 0.94 \\
\hline Emberiza cioides & 0.55 & E. cioides & 0.68 & E. cioides & 0.58 \\
\hline $\begin{array}{l}\text { Cuculus } \\
\text { poliocephalus }\end{array}$ & 0.47 & P. minor & 0.56 & C. macrorhynchos & 0.55 \\
\hline $\begin{array}{l}\text { Corvus } \\
\text { macrorhynchos }\end{array}$ & 0.45 & C. macrorhynchos & 0.53 & C. poliocephalus & 0.42 \\
\hline Parus minor & 0.47 & $\begin{array}{l}\text { Streptopelia } \\
\text { orientalis }\end{array}$ & 0.50 & $\begin{array}{l}\text { Acrocephalus } \\
\text { arundinaceus }\end{array}$ & 0.42 \\
\hline Phasianus versicolor & 0.39 & C. poliocephalus & 0.47 & P. minor & 0.33 \\
\hline Carduelis sinica & 0.32 & P. versicolor & 0.35 & Poecile varius & 0.27 \\
\hline Zosteropus japoniucs & 0.26 & Passer montanus & 0.26 & $P$. versicolor & 0.24 \\
\hline $\begin{array}{l}\text { Streptopelia } \\
\text { orientalis }\end{array}$ & 0.26 & Garrulax canorus & 0.24 & Passer montanus & 0.21 \\
\hline
\end{tabular}

the most dominant $C$. diphone. Overall, these seven species are common as edge species or users of variable ecosystems. Acrocephalus arundinaceus is a common summer visitor that has a loud call. It inhabits marshlands and breeds in reed beds. This species may have immigrated earlier or more in 2014 than the other years, and was recorded in the point counts conducted during mid-June. These seven or eight 
dominant species might be good indicator birds of environmental change and/or radiation effects in this area (Gregory and Strien 2010).

Other species are less common and their populations fluctuate annually. For instance, Passer montanus is a common species around human houses and paddies all over Japan. Streptopelia orientalis, the common pigeon in low elevations in Japan, was also frequently observed much more in 2011. Pigeons and doves are strong flyers and can quickly change their distribution depending on their food resource. Carduelis sinica was observed at more than $20 \%$ of point count sites in 2013, Garrulax canorus more in 2012, and Zosteropus japoniucs more in 2014. Poecile varius was dominant only in 2014. It will depend on the future observations as to whether these species will contribute toward change in the wildlife after the F1NPP accident.

\subsection{Heterogeneity of Microhabitat Radioactivity}

It has been proven that radioactive substances, ${ }^{137} \mathrm{Cs}$ and ${ }^{134} \mathrm{Cs}$, strongly fix to clay soils in the ecosystem (Chap. 1). The purpose of many studies in Fukushima is to investigate the dynamics of Cs within and among the ecosystems. Their macrodistribution has been well examined and published on the web (MEXT 2011). It is also well known that there are hotspots and that dose rates are higher close to the ground. I examined dose rates in the field with dosimeter badges (type ES, Chiyoda Technol Co. Ltd., Tokyo) set at tree trunks for about 2 months.

The dose rates at about $1 \mathrm{~m}$ above the ground in forest stands decreased according to the half-life of ${ }^{137} \mathrm{Cs}$ and ${ }^{134} \mathrm{Cs}$, and they were lower during the season with snow accumulation (Figs. 10.5 and 10.7).

I set about 100 dosimeter badges at each of the two locations to examine the microhabitat heterogeneity of radioactivity during December in 2012 and January in 2013. One location was at Techiro, Akaugi, Namie Town $\left(37^{\circ} 35^{\prime} 33^{\prime \prime} \mathrm{N}\right.$, $140^{\circ} 45^{\prime} 14^{\prime \prime} \mathrm{E}$ ) in a high contamination area, and the other was located at Kamitashiro, Yamakiya, Kawamata Town $\left(37^{\circ} 34^{\prime} 6^{\prime \prime} \mathrm{N}, 140^{\circ} 41^{\prime} 36^{\prime \prime}\right)$ in a low contamination area (Fig. 10.4). The badges were located within a 300-m radius at Techiro, and within a 200-m radius at Kamitashiro (Fig. 10.8). Most were set on the tree trunks at $0 \mathrm{~m}$ (on the ground), $1.2 \mathrm{~m}$ (breast height) and $2 \mathrm{~m}$ (head height). Some were set in a plastic tube at $0.15-\mathrm{m}$ depth in the ground, and up to 11 or $12 \mathrm{~m}$ above the ground on tree trunks or on a tower (Fig. 10.8).

Higher radioactivity was recorded on the ground, and the radioactivity decreased according to the vertical distance from the ground increased (Fig. 10.9). Although only one or two samples were taken at $0.15-\mathrm{m}$ depth, the radioactivity was lower than that of samples on the ground surface at the same places. For samples measured on a deciduous tree trunk, the radiation decreased in a non-linear fashion relative to the distance from the ground (Fig. 10.8, right); probably because the radioactive substances remained either in the bark, or in the moss or lichen on the bark. The dose rates heterogeneity was high among the microhabitats within a small 


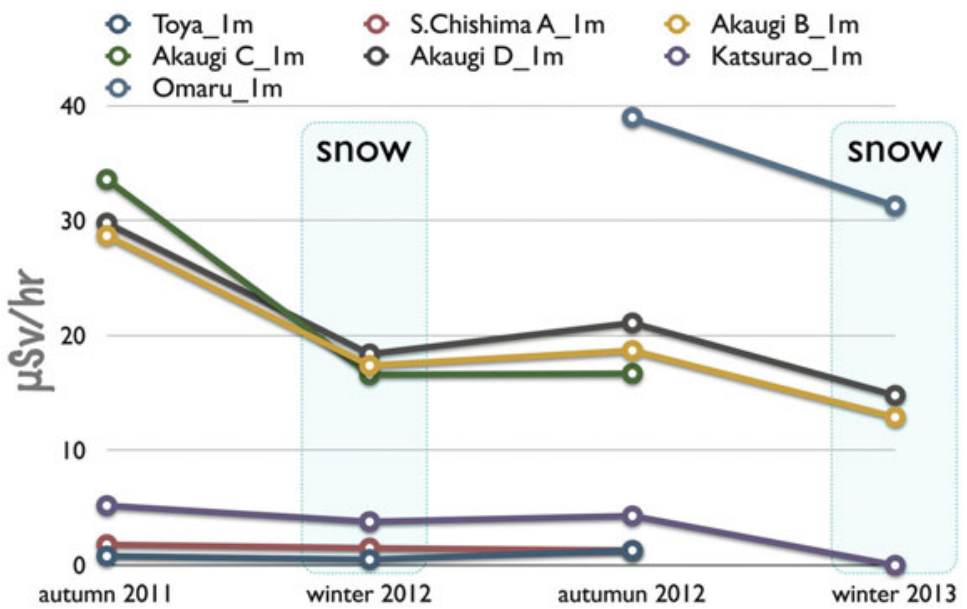

Fig. 10.7 Ecological decline process of aerial dose rate at several contaminated districts in Fukushima

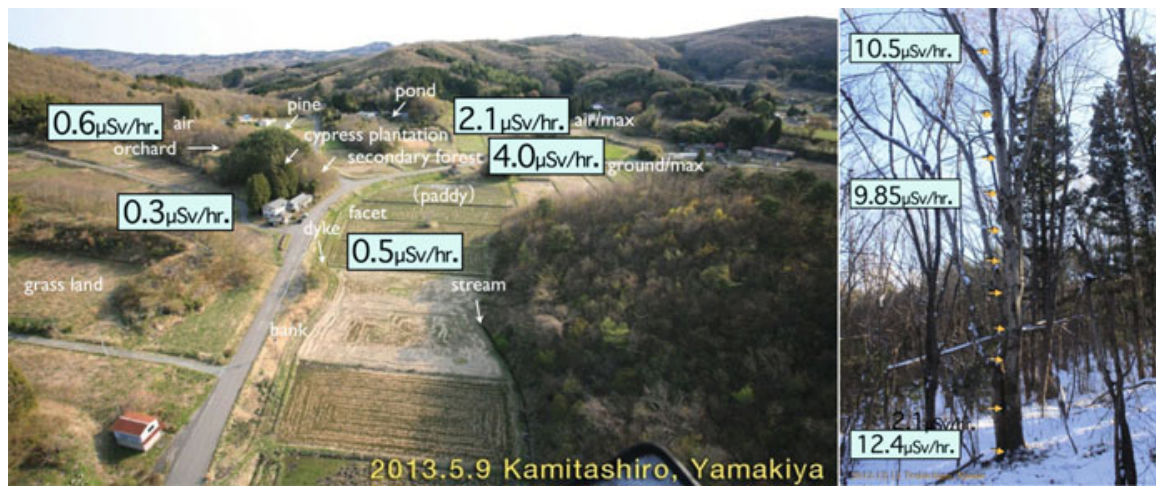

Fig. 10.8 Outline profile of aerial dose rate microhabitat heterogeneity, which depends the distance (height) from the soil (ground), direction towards F1NPP, surrounding topology, vegetation, and artificial management. (a) Aerial view taken from the southwest with a motor hung glider: some main microhabitats and their dose rates at Kamitashiro, Yamakiya of Kawamata Town (F1NPP is right forward), (b) an oak tree and its dose rates along its trunk (0 to about $11 \mathrm{~m}$ from the ground) at Techiro, Akaugi of Namie Town. The dose rates on the ground was $12.4(\mu \mathrm{Sv} / \mathrm{h})$ and at the height of $11 \mathrm{~m}$ was $10.5(\mu \mathrm{Sv} / \mathrm{h})$. See also Fig. 10.9

area. The dose rates in Kamitashiro and in Techiro varied tenfold and threefold, respectively (Fig. 10.9). The dose rates depended on the direction of the slopes in which each microhabitat located with respect to F1NPP and on a small scale (several meters) and large scale geometric structures (Fig. 10.8, left). 
Fig. 10.9 Microhabitat heterogeneity of aerial dose rate at two sites, estimated with dosimeter glass badges (type ES, Chiyoda Technol Co. Ltd., Tokyo) fitted for 2 months in the field. Abbreviations: $I G$ in the ground (15-cm depth), $O G$ on the ground, $\mathrm{BH}$ breath height (1-1.2 $\mathrm{m}$ above the ground), $H H$ head height $(\sim 2 \mathrm{~m}), I A$ in the air $(>3 \mathrm{~m})$

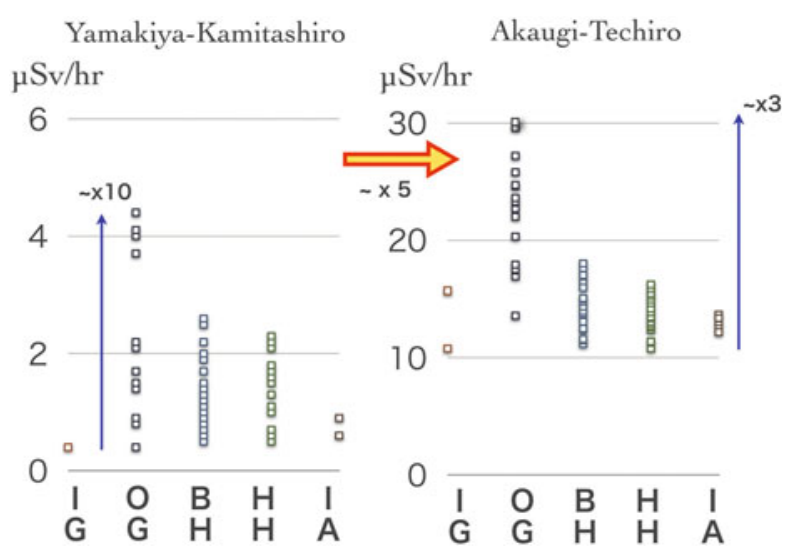

\subsection{Effects of Radioactivity on Bush Warbler and Boar}

The bush warbler (Cettia diphone) is the most dominant bird, and its microhabitat is the dense bush at lower heights, usually up to $2 \mathrm{~m}$ from the ground, in a variety of vegetation and ecosystems from the coast to the mountaintop. Wild boar (Sus scrofa) is a common mammal in the forest and grasslands, and Abukuma highland is the northernmost border of its distribution in Japan. The boar is omnivorous and often forages for various things by digging into the soil with its strong nose. Therefore, both of these animals have a high probability of being close to the radioactive substances in the contaminated area of Fukushima, and should be two of the best indicator species to monitor the effects of the F1NPP accident on freeliving animals.

Tail feathers (Pirastro et al. 1993) of the bush warblers, caught at Akaugi, were contaminated with up to $556 \mathrm{~Bq} / \mathrm{g}$ of ${ }^{137} \mathrm{Cs}$, ${ }^{134} \mathrm{Cs}$, and ${ }^{110 \mathrm{~m}} \mathrm{Ag}$ in mid-August 2011 (Ishida 2013). The contamination level of feathers at the same site decreased to about $20 \%$ in 2012 and contamination became less frequent among the individuals in 2013. Fukushima Prefecture (2014) published radioactivity measurements of the muscle of game animals, including boar, on its website. For this study, I picked up a total of 680 samples collected from boars, caught in Fukushima during the period of 22th May 2011 until 20th August 2014. The dose rates ranged from "not detected" $\left({ }^{137} \mathrm{Cs}<5.5 \mathrm{~Bq} / \mathrm{kg}\right.$ and ${ }^{134} \mathrm{Cs}<<4.0 \mathrm{~Bq} / \mathrm{kg}$ ) to $61 \mathrm{~Bq} / \mathrm{g}$ (a boar from Minamisoma City on 11 March, 2013). The highest value in 2014 was $2.4 \mathrm{~Bq} / \mathrm{g}$ (a boar from Minamisoma City on 27 July). Wildlife exposure measurements started soon after the F1NPP accident, and long term monitoring of these animals may contribute to our understanding the dynamics of radioactive substances in the ecosystem (and evnvironmental protection; ICRP 2008). 


\subsection{Environmental Factors that Affect Wildlife}

Microhabitat heterogeneity of radioactivity was as large as tenfold (Fig. 10.9). The long, low, and internal exposure to radiation (ECRR 2010) by wildlife depends on the species, on the behavior of individual animals, and on where and when it is present at which microhabitat. The difference in microhabitat radiation caused by the direction with respect to F1NPP can affect these animals incidentally. It is first necessary to determine the individual exposure as much as possible or to sample as many individuals as possible to account for the individual variation. Environmental factors, which were caused by F1NPP accident and thought to relate to wildlife fitness change, include radioactivity as well as the numerous interactive changes. Both of these environmental factors have a direct and indirect effect, and sometimes their effects cascade through food webs (Hallmann et al. 2014). At least in the early years of 2011 and 2012, there seemed to be a notable decrease in butterfly fitness in the contaminated areas of northern Abukuma highland (Hiyama et al. 2012; Møller et al. 2013). I tried to catch butterflies at highly contaminated areas such as at Akaugi and Omaru (Fig. 10.4) during the 2012 summer, but I could not find any. Then, I found some in the summer of 2013, and more in 2014. Butterflies and some other insects are an important food resource for insectivorous birds, too. Human activity, including cultivation of the agricultural land, cutting timbers, hunting, and collecting woods, mushrooms and bamboo shoots, has stopped in the high contamination areas and in some parts of the low contamination areas. Most of the low contamination areas, where people are expected to return to live in several years, were decontaminated in an extreme manner. The soil and the lower vegetation were removed. This resulted in a loss of several microhabitats and biodiversity at these sites. In high contamination areas, where people are not expected to return for at least several decades, the land has been left without human activity and some wildlife has increased in density, because of the lack of hunting by humans. All of the complex interactions in an ecosystem should affect the bird community, and we should consider and detect more than the few most important factors.

Cettia diphone, for example, may have some advantage by inhabiting dense bush at the abandoned agricultural land and secondary forest edge for a while until the forests regrown, and some disadvantage by the fewer hymenopteran insects (Hallmann et al. 2014) and the removal of the bush as part of the extreme decontamination activity. As $C$. diphone stays close to the ground, it could be affected by the radiation at least over the first couple of years, while the dose rate in the air is rather high. Hypsipetes amourotis is an arboreal bird and is active within the forest canopy. It is omnivorous and has a large home range; hence, the various environmental changes could be neutral for this bird. Emberiza cioides is a seedeater and is a stable settler in its small territory. It often feeds on seeds of shorter grasses and also on the ground, so its exposure situation resembles that of $C$. diphone, except for their food feeding habits. I currently do not have enough information about seed production in the highly contaminated area, but as the F1NPP accident occurred prior to the rapid growth of plant shoots in spring, seed production seemed to be less affected by the radiation. 
Phasianus versicolor is a ground dwelling bird and is omnivorous. It forages and nests on the ground. It is a game bird. There should be multiple responses by this species to the environmental changes. Unfortunately, there is very little information on the wildlife in the contaminated area of Abukuma Mountains before the F1NPP accident. It will be desirable to monitor the ecosystem and several principal wildlife species, such as some of the dominant 10 birds (explained previously), S. scrofa and unique primate Macaca fuscata (Hayama et al. 2013), until most of the ecosystems and human societies regain stability in five or more decades later (Galvan et al. 2014).

Open Access This chapter is distributed under the terms of the Creative Commons Attribution Noncommercial License, which permits any noncommercial use, distribution, and reproduction in any medium, provided the original author(s) and source are credited.

\section{References}

Akimoto S (2014) Morphological abnormalities in gall-forming aphids in a radiationcontaminated area near Fukushima Daiichi: selective impact of fallout? Ecol Evol 4:355-369

European Committee on Radiation Risk (2010) In: Busby C (ed) Recommendations of the European committee on radiation risk. The health effects of exposure to low doses of ionizing radiation, p 248. http://www.euradcom.org/2011/ecrr2010.pdf

Fukushima Prefecture (2014) Data of wildlife radiation monitoring (in Japanese). http://www.pref. fukushima.lg.jp/sec/16035b/wildlife-radiationmonitoring1.html

Galvan I, Bonisoli-Alquati A, Jenkinson S, Ghanem G, Wakamatsu K, Mousseau SA, Møllor AP (2014) Chronic exposure to low-dose radiation at Chernobyl favours adaptation to oxidative stress in birds. Funct Ecol 28:1387-1403

Gregory RD, van Strien A (2010) Wild bird indicators: using composite population trends of birds as measures of environmental health. Ornithol Sci 9:3-22

Hallmann CA, Foppen RPB, van Turnhout CAM, Kroon H, Jongejans E (2014) Declines in insectivorous birds are associated with high neonicotinoid concentrations. Nature. doi:10.1038/nature13531

Hayama S, Nakiri S, Nakanishi S, Ishii N, Uno T, Kato T, Konno F, Kawamoto Y, Tsuchida S, Ochiai K, Omi T (2013) Concentration of radiocesium in the wild Japanese monkey (Macaca fuscata) over the first 15 months after the Fukushima Daiichi disaster. PLoS ONE. doi:10.1371/ journal.pone. 0068530

Hiyama A, Nohara C, Kinjo S, Taira W, Gima S, Tnahara A, Otaki JM (2012) The biological impacts of the Fukushima nuclear accident on the pale grass blue butterfly. Sci Rep 2:570. doi:10.1038/srep00570

ICRP (2008) Environmental protection - the concept and use of reference animals and plants. http://www.icrp.org/publication.asp?id=ICRP\%20Publication\%20108

Ishida K (2013) Contamination of wild animals: effects on wildlife in high radioactivity areas of the agricultural and forest landscape. In: Nakanishi TM, Tanoi K (eds) Agricultural implications of the Fukushima nuclear accident. Springer, Tokyo, pp 119-129. doi:10.1007/978-4431-54328-2_12

MEXT (2011) Press release on the airborne survey results 1910-1125_2, p 27 (in Japanese). http:// radioactivity.nsr.go.jp/ja/contents/5000/4900/24/1910_1125_2.pdf

Møller AP, Nishiumi I, Suzuki H, Ueda K, Mousseaue TA (2013) Differences in effects of radiation on abundance of animals in Fukushima and Chernobyl. Ecol Indic 24:75-81

Pirastro A, Congiu L, Tallandini L, Turchetto M (1993) The use of bird feathers for the monitoring of cadmium pollution. Arch Environ Contam Toxicol 24:355-358 